\title{
Genetic association of angiogenesis- and hypoxia-related gene polymorphisms with osteonecrosis of the femoral head
}

\author{
Jung Min Hong ${ }^{1,2}$, Tae-Ho Kim ${ }^{1}$, \\ Hyun-Ju Kim ${ }^{1}$, Eui-Kyun Park ${ }^{1,3}$, \\ Eun-Kyoung Yang ${ }^{2,5}$ and Shin-Yoon Kim ${ }^{1,4,5}$ \\ ${ }^{1}$ Skeletal Diseases Genome Research Center \\ Kyungpook National University Hospital \\ ${ }^{2}$ Department of Physiology \\ Kyungpook National University School of Medicine \\ ${ }^{3}$ Department of Pathology and Regenerative Medicine \\ School of Dentistry, Kyungpook National University \\ Daegu 700-412, Korea \\ ${ }^{4}$ Department of Orthopedic Surgery \\ Kyungpook National University School of Medicine \\ Daegu 700-712, Korea \\ ${ }^{5}$ Corresponding authors: Tel, 82-53-420-6927; \\ Fax, 82-53-424-3349; E-mail, ekyang @ mail.knu.ac.kr (E.K.Y.) \\ Tel, 82-53-420-5635; Fax, 82-53-422-6605; \\ E-mail, syukim @knu.ac.kr (S.Y.K.) \\ DOI 10.3858/emm.2010.42.5.039
}

Accepted 8 March 2010

Available Online 10 March 2010

Abbreviations: HWE, Hardy-Weinberg equilibrium; LD, linkage disequilibrium; MAF, minor allele frequency; ONFH, osteonecrosis of the femoral head; SNP, single nucleotide polymorphism

\begin{abstract}
Multiple factors have been implicated in the development of osteonecrosis of the femoral head (ONFH). In particular, non-traumatic ONFH is directly or indirectly related to injury of the vascular supply to the femoral head. Thus, hypoxia in the femoral head caused by impaired blood flow may be an important risk factor for ONFH. In this study, we investigated whether genetic variations of angiogenesis- and hypoxia-related genes contribute to an increased risk for the development of ONFH. Candidate genes were selected based on known hypoxia and angiogenesis pathways. An association study was performed using an Affymetrix Targeted Genotyping 3K Chip array with 460 ONFH patients and 300 control subjects. We showed that single nucleotide polymorphisms (SNPs) in the genes TF, VEGFC, IGFBP3, and ACE were associated with an increased risk of ONFH. On the other hand, SNPs in the $K D R$ and NRP1 genes were associated with protection
\end{abstract}

against ONFH. The most important finding was that one SNP (rs2453839) in the IGFBP3 gene was significantly associated with a higher risk of ONFH $(P=$ 0.0061, OR 7.74). In subgroup analysis, most candidate gene variations that were associated with ONFH occurred in the idiopathic subgroup. Among other SNPs, $A C E$ SNPs were associated with steroid-induced ONFH $(P=0.0018-0.0037$, OR $>3)$. Collectively, our findings suggest that genetic variations in angiogenesis- and hypoxia-related genes may help to identify susceptibility factors for the development of ONFH in the Korean population.

Keywords: anoxia; Asian continental ancestry group; femur head; neovascularization, physiologic; osteonecrosis; polymorphism, single nucleotide

\section{Introduction}

Osteonecrosis of the femoral head (ONFH) is a bone disorder that usually affects middle-aged men 30-50 yr of age (Jones, 1999; Glueck et al., 2003). Various factors have been implicated in the development of ONFH. However, the exact pathogenesis of non-traumatic ONFH is largely unknown, although it has been associated with corticosteroid usage, alcoholism, infections, marrow infiltrating diseases, and coagulation defects (Jones, 1999; Glueck et al., 2003; Childs, 2005). Most of these risk factors are closely related to direct or indirect injury to the vascular supply of the femoral head.

Genetic associations between ONFH and hypofibrinolysis or thrombophilia along with coagulation have been reported (Glueck et al., 2001; Bjorkman et al., 2004). Coagulation-related factors including plasminogen-activating inhibitor-1 (PAl-1), Factor $\mathrm{V}$ (F5), prothrombin, and methylenetetrahydrofolate reductase (MTHFR) are associated with ONFH development. Therefore, many studies have proposed that a pathogenetic mechanism, such as coagulation and angiogenesis, also seems to be major risk factor for osteonecrosis (ON).

Angiogenesis is a physiological process involving the growth of new blood vessels for the blood supply. Also, angiogenesis is essential for development, wound healing of most tissues, and bone remodeling (Colnot et al., 2003; Fong et al., 2003). 
Vascular endothelial growth factor (VEGF), an essential regulator for angiogenesis, plays a key role in vascular endothelial cell migration, proliferation, and permeability. In particular, VEGF is important for bone formation processes such as morphogenesis of a normal growth plate, including blood vessel invasion and cartilage remodeling (Harper and Klagsbrun, 1999; Komatsu and Hadjiargyrou, 2004). In addition, VEGF is highly expressed in the edematous zone of ON adjacent to the necrotic area, indicating that it might be an important factor for bone tissue repair (Radke et al., 2006). Another angiogenic factor, PAl-1, is also highly expressed in dysbaric osteonecrosis (Miyanishi et al., 2002). Many studies have shown that VEGF enhances blood flow in necrotic bone or avascular bone (Suzuki et al., 2004; Ma et al., 2007). These studies have suggested that the genetic variations in angiogenesis-related gene may affect the development of ONFH (Kerachian et al., 2006).

A hypoxic condition is the first stimulus for angiogenesis (Arnett et al., 2003; Lin et al., 2004). Disruption of the blood supply to damaged bone often causes hypoxia (Glowacki, 1998; Lewis et al., 1999) and, thus, a loss of blood supply (Arnett et al., 2003; Childs, 2005). Consequently, hypoxia is known to induce both apoptosis and necrosis of cells and is associated with various vascular diseases including cardiovascular disease, cerebral ischemia, pulmonary hypertension, and cancer (Semenza, 2000; Lattimore et al., 2005). In particular, hypoxia accelerates atherosclerosis by promoting the accumulation of lipid loading in the arterial wall (Lattimore et al., 2005). Many studies have shown that hypoxia activates a number of cell regulatory processes including angiogenesis, erythropoiesis, energy metabolism, cell survival, and iron homeostasis (Semenza, 2001; Hickey and Simon, 2006). During the bone regeneration typically seen in fracture repair or distraction osteogenesis, the expression of hypoxia-inducible factor- $1 \alpha$ (HIF-1 $\alpha$ ) and its target genes, such as VEGF, was directly correlated with cellular survival, and blood vessel and callus formation (Komatsu and Hadjiargyrou, 2004). In a previous study, HIF-1 also was shown to bind to the VEGF promoter and form a complex that activates transcription of the VEGF gene (Stein et al., 1998). Hypoxia leads to enhanced bone regeneration by inhibiting chondrocyte and osteoblast apoptosis (Komatsu et al., 2007). Hypoxia also develops in bone fractures and in the joints of patients with rheumatoid arthritis (RA), leading to necrosis (Lewis et al., 1999). In fact, we previously have shown that a polymorphism in the HIF-1 $\alpha$ gene is closely associated with ONFH
(Hong et al., 2007).

A number of studies have reported that hypoxia and angiogenesis are related to the biological pathways of bone diseases, including ONFH (Lewis et al., 1999; Semenza, 2000; Radke et al., 2006). However, the genetic link between hypoxia and angiogenesis and ONFH is not yet known. In this study, we attempted to determine whether allelic variations in angiogenesis- and hypoxia-related genes are associated with the progression and pathogenesis of ONFH.

\section{Results}

To identify genetic factors involved in susceptibility to ONFH, we conducted an association study using SNP chip array data in 460 ONFH patients and 300 controls. Candidate genes were selected from previous microarray reports (Pacicca et al., 2003; Wieczorek et al., 2003; Salim et al., 2004; Tardif et al., 2004; Fang et al., 2005; Hopwood et al., 2005; Zhou et al., 2005). SNPs in these genes were selected based on a call rate $(\mathrm{CR})>0.90$, minor allele frequency (MAF) $>0.05$, and Hardy-Weinberg equilibrium (HWE) $>0.05$ using a public database (http://www.ncbi.nlm.nih.gov/SNP/). Total numbers of SNPs found in genes related to angiogenesis (31 genes) and the SNPs selected for genotyping (212 SNPs) are listed in Supplemental Data Table S1.

Among them, our results reveal that 6 candidate genes (TF, KDR, VEGFC, IGFBP3, NRP1 and ACE) are significantly associated with ONFH (Supplemental Data Table S2). SNP IDs, MAF, and HWE of the genotyped SNPs are presented in Supplemental Data Table S2. The genotype distributions between ONFH patients and control groups were compared and applied to the Hardy-Weinberg equilibrium (Supplemental Data Table S2). Each genotype was also analyzed with the use of codominant, dominant, recessive, and allele genetic models.

We found significant associations of genotypic and allelic frequencies for several SNPs of candidate genes with ONFH (Table 1). Three SNPs (rs1880669, rs2692695, rs2718806) of the Transferrin (TF) gene showed association with ONFH in the codominant and dominant models $(P$ $=0.0049-0.0448$, OR 1.27-1.69). Two SNPs (rs1485766, rs3775203) of Vascular endothelial growth factor $C$ (VEGFC) were also associated with increased risk of ONFH $(P=0.0042-0.0107$, OR 1.33-1.67). A significant association for three SNPs (rs4309, rs4344, rs4461142) of Angiotensin I converting enzyme (ACE) was also found in the 
Table 1. Association between candidate gene polymorphisms and ONFH among ONFH cases and controls.

\begin{tabular}{|c|c|c|c|c|c|c|c|c|}
\hline \multirow{3}{*}{ Gene } & \multirow{3}{*}{ SNP rs ID } & \multirow{3}{*}{ Position } & \multirow{3}{*}{ Genotype } & \multirow{3}{*}{$\begin{array}{c}\text { ONF } \\
\text { patients }\end{array}$} & \multirow{3}{*}{$\begin{array}{l}\text { Normal } \\
\text { controls }\end{array}$} & Codominant & Dominant & Recessive \\
\hline & & & & & & OR $(95 \% \mathrm{Cl})^{\mathrm{a}}$ & OR $(95 \% \mathrm{Cl})^{\mathrm{a}}$ & OR $(95 \% \mathrm{Cl})^{\mathrm{a}}$ \\
\hline & & & & & & $P^{a}$ & $P^{a}$ & $P^{a}$ \\
\hline \multirow[t]{12}{*}{ TF } & rs1880669 & Intron10 & TT & $103(23.41)$ & $83(30.86)$ & $1.23(0.99-1.52)$ & $1.50(1.06-2.11)$ & $1.14(0.80-1.63)$ \\
\hline & & & $\mathrm{TC}$ & $224(50.91)$ & $124(46.1)$ & 0.0635 & 0.0208 & 0.4780 \\
\hline & & & $\mathrm{CC}$ & $113(25.68)$ & $62(23.05)$ & & & \\
\hline & rs2692695 & Intron12 & GG & $82(19.52)$ & 75 (28.3) & $1.27(1.02-1.59)$ & $1.69(1.17-2.43)$ & $1.13(0.79-1.61)$ \\
\hline & & & GA & $225(53.57)$ & $125(47.17)$ & 0.0345 & 0.0049 & 0.5044 \\
\hline & & & $A A$ & $113(26.9)$ & $65(24.53)$ & & & \\
\hline & rs2718806 & Intron12 & GG & $366(83.18)$ & $242(88.64)$ & $1.57(1.01-2.43)$ & $1.62(1.03-2.55)$ & $1.20(0.11-13.35)$ \\
\hline & & & GA & $72(16.36)$ & 30 (10.99) & 0.0448 & 0.0384 & 0.8826 \\
\hline & & & $A A$ & $2(0.45)$ & $1(0.37)$ & & & \\
\hline & rs1525889 & Intron14 & $A A$ & $139(32.1)$ & 99 (36.94) & $1.10(0.87-1.37)$ & $1.26(0.91-1.74)$ & $0.93(0.61-1.41)$ \\
\hline & & & $A C$ & $225(51.96)$ & $125(46.64)$ & 0.4274 & 0.1591 & 0.7333 \\
\hline & & & $\mathrm{CC}$ & $69(15.94)$ & $44(16.42)$ & & & \\
\hline \multirow[t]{6}{*}{ KDR } & rs6837735 & Intron2 & $\mathrm{CC}$ & $128(29.16)$ & $69(25.37)$ & $0.80(0.64-1.00)$ & $0.82(0.58-1.16)$ & $0.67(0.47-0.97)$ \\
\hline & & & $\mathrm{CT}$ & 230 (52.39) & 135 (49.63) & 0.0521 & 0.2713 & 0.0357 \\
\hline & & & TT & $81(18.45)$ & $68(25)$ & & & \\
\hline & rs1870377 & Exon11 & $\mathrm{TT}$ & $140(32.48)$ & $95(34.8)$ & $0.94(0.75-1.17)$ & $1.13(0.82-1.56)$ & $0.67(0.45-0.99)$ \\
\hline & & & TA & $229(53.13)$ & $122(44.69)$ & 0.5732 & 0.4547 & 0.0488 \\
\hline & & & AA & $62(14.39)$ & $56(20.51)$ & & & \\
\hline \multirow[t]{9}{*}{ VEGFC } & rs1485766 & Intron4 & $\mathrm{TT}$ & $90(20.32)$ & $80(29.3)$ & $1.37(1.10-1.71)$ & $1.67(1.18-2.38)$ & $1.37(0.96-1.97)$ \\
\hline & & & TG & $233(52.6)$ & $134(49.08)$ & 0.0050 & 0.0042 & 0.0861 \\
\hline & & & GG & $120(27.09)$ & $59(21.61)$ & & & \\
\hline & rs2333496 & Intron4 & TT & $185(42.24)$ & $108(40.3)$ & $0.82(0.66-1.03)$ & $0.92(0.67-1.25)$ & $0.55(0.35-0.86)$ \\
\hline & & & $\mathrm{TC}$ & 208 (47.49) & $114(42.54)$ & 0.0897 & 0.5872 & 0.0087 \\
\hline & & & $\mathrm{CC}$ & $45(10.27)$ & $46(17.16)$ & & & \\
\hline & rs3775203 & Intron4 & TT & $100(22.83)$ & $84(31)$ & $1.33(1.07-1.65)$ & $1.57(1.11-2.21)$ & $1.36(0.94-1.95)$ \\
\hline & & & TG & $222(50.68)$ & $129(47.6)$ & 0.0103 & 0.0107 & 0.1016 \\
\hline & & & GG & $116(26.48)$ & $58(21.4)$ & & & \\
\hline \multirow[t]{6}{*}{ IGFBP3 } & rs3110697 & Intron3 & GG & $237(54.48)$ & 139 (52.65) & $1.07(0.83-1.38)$ & $0.95(0.69-1.29)$ & $2.085(1.03-4.22)$ \\
\hline & & Intron4 & GA & $164(37.7)$ & $114(43.18)$ & 0.5874 & 0.7203 & 0.0412 \\
\hline & & & AA & $34(7.82)$ & $11(4.17)$ & & & \\
\hline & rs2453839 & & TT & $293(66.14)$ & $191(70.48)$ & $1.37(1.02-1.82)$ & $1.23(0.88-1.71)$ & $7.74(1.79-33.41)$ \\
\hline & & & $\mathrm{TC}$ & $128(28.89)$ & $78(28.78)$ & 0.0351 & 0.2184 & 0.0061 \\
\hline & & & $\mathrm{CC}$ & $22(4.97)$ & $2(0.74)$ & & & \\
\hline \multirow[t]{9}{*}{ NRP1 } & rs12573218 & Intron2 & $\mathrm{CC}$ & $290(73.6)$ & $153(62.96)$ & $0.60(0.43-0.83)$ & $0.59(0.42-0.84)$ & $0.32(0.07-1.36)$ \\
\hline & & & CT & $101(25.63)$ & 85 (34.98) & 0.0019 & 0.0033 & 0.1218 \\
\hline & & & TT & $3(0.76)$ & $5(2.06)$ & & & \\
\hline & rs12358370 & Intron2 & $\mathrm{CC}$ & $399(90.27)$ & 231 (84.62) & $0.56(0.36-0.87)$ & $0.55(0.35-0.87)$ & $0.31(0.03-3.57)$ \\
\hline & & & CG & $42(9.5)$ & $40(14.65)$ & 0.0096 & 0.0109 & 0.3485 \\
\hline & & & GG & $1(0.23)$ & $2(0.73)$ & & & \\
\hline & rs2269091 & Intron6 & GG & $304(69.89)$ & $164(62.84)$ & $0.74(0.55-0.98)$ & $0.72(0.52-1.01)$ & $0.55(0.21-1.46)$ \\
\hline & & & GT & $123(28.28)$ & 88 (33.72) & 0.0382 & 0.0532 & 0.2308 \\
\hline & & & TT & $8(1.84)$ & $9(3.45)$ & & & \\
\hline \multirow[t]{9}{*}{ ACE } & rs4309 & Exon8 & TT & $121(27.44)$ & $100(36.76)$ & $1.24(0.99-1.54)$ & $1.50(1.08-2.08)$ & $1.09(0.73-1.62)$ \\
\hline & & & TC & $239(54.2)$ & 124 (45.59) & 0.0627 & 0.0147 & 0.6833 \\
\hline & & & $\mathrm{CC}$ & $81(18.37)$ & $48(17.65)$ & & & \\
\hline & rs4344 & Intron17 & $A A$ & $129(29.72)$ & $98(37.26)$ & $1.17(0.93-1.47)$ & $1.42(1.02-1.96)$ & $0.98(0.65-1.48)$ \\
\hline & & & $A G$ & $235(54.15)$ & $120(45.63)$ & 0.1709 & 0.0367 & 0.9050 \\
\hline & & & GG & $70(16.13)$ & $45(17.11)$ & & & \\
\hline & rs4461142 & Intron26 & $\mathrm{CC}$ & $107(24.6)$ & 94 (34.69) & $1.34(1.07-1.68)$ & $1.63(1.16-2.28)$ & $1.26(0.84-1.87)$ \\
\hline & & & $\mathrm{CT}$ & $241(55.4)$ & $131(48.34)$ & 0.0113 & 0.0044 & 0.2596 \\
\hline & & & TT & $87(20)$ & 46 (16.97) & & & \\
\hline
\end{tabular}

${ }^{a}$ Logistic regression analyses were used for calculating the $\mathrm{OR}(95 \% \mathrm{Cl})$ and $P$-value. 
dominant model $(P=0.0044-0.0367$, OR 1.34-1.63). The most significant association with risk of ONFH was identified in a single SNP (rs2453839) of the Insulin-like growth factor binding protein 3 (IGFBP3) gene in the recessive model $(P=0.0061$, OR 7.74$)$ (Table 1).

On the other hand, several SNPs in the Kinase insert domain receptor (KDR), VEGFC, and Neuropilin 1 (NRP1) genes showed a protective effect against ONFH. Two SNPs (rs6837735, rs1870377) of KDR were associated with a protective effect against $\mathrm{ONFH}$ in the recessive model $(P=0.0357,0.0488$, OR $0.67,0.67$, respectively). SNP rs2333496 of VEGFC ( $P=0.0087$, OR 0.55 ) and three SNPs (rs12573218, rs12358370, rs2269091) of NRP1 $(P=0.0019-0.0423$, OR $0.55-0.75)$ were associated with a reduced risk of $\mathrm{ONFH}$. There were no statistically significant interactions between any other SNPs and ONFH (Table 1).

For further analysis, we classified ONFH cases on the basis of pathological etiology into three subgroups (alcohol-induced, idiopathic, and steroid-induced, Table 2). We found that a significant association was found between SNPs in the TF gene and the idiopathic subgroup $(P=0.0008-$ 0.0486 , OR 1.38-2.37). This result suggests that TF gene variations are risk factors for increased susceptibility to idiopathic ONFH. Two SNPs (rs1485766, rs3775203) in the VEGFC gene were also associated with the risk of developing ONFH in the alcohol and idiopathic subgroups $(P=0.0259$ 0.0347, OR 1.34-1.59 and $P=0.0010-0.0456$, OR 1.38-2.26, respectively). In addition, three SNPs (rs4309, rs4344, rs4461142) in ACE were associated with susceptibility to ONFH in the steroid subgroup $(P=0.0018-0.0037$, OR 3.26-3.68 in the dominant model). However, one SNP (rs6837735) of KDR $(P=$ 0.0011-0.0107, OR 0.42-0.70) and three SNPs (rs12573218, rs12358370, rs2269091) of NRP1 $(P=$ 0.01120 .0446 , OR $0.49-0.68$ ) had protective effects in the idiopathic subgroup. The most significant association was found in the IGFBP3 gene. SNP (rs2453839) was significantly associated with alcohol-induced and idiopathic ONFH in the recessive model. The odds ratio of the susceptibility allele was $6.15(P=0.0194)$ and $8.67(P=0.0066)$ in the two subgroups, respectively. This result suggests that subjects carrying the minor homozygous allele (CC) of rs2453839 tend to have a higher risk of developing ONFH (Table 2).

We also constructed an LD and performed haplotype analyses based on genotype data of SNPs in the candidate genes. The haplotypes with a MAF $\geq 5 \%$ were observed within an LD block. There is one LD block in the TF gene, three LD blocks in the KDR gene, one LD block in the IGFBP3 gene, five LD blocks in the NRP1 gene, and two LD blocks in the ACE gene (Supplemental Data Figure S1A-F). Several haplotypes were found to be associated with ONFH (Table 3). Subjects carrying the KDR-ht6 allele $(42 \%)$ had a higher risk of ONFH than those not carrying the KDR-ht6 allele (35\%) $(P=0.146$, OR 1.32). However, TF-ht2 $(P=0.0151$, OR 0.72$)$ and KDR-ht10 $(P=0.0026$, OR 0.52$)$ were associated with a reduced risk of ONFH, which was not predicted by individual SNP analyses. NRP1-ht16 was also related to a decreased ONFH risk $(P=0.0118$, OR $0.67)$. There were no significant differences in candidate genes between the other haplotypes and ONFH (Table 3).

\section{Discussion}

Many studies have shown that the correlation between hypoxia and the regulation of angiogenesis is a significant component of homeostatic mechanisms (Semenza, 2000; Semenza, 2001). Hypoxia is a primary stimulus for angiogenesis and is associated with various vascular diseases (Semenza, 2000, 2001), including osteonecrosis (Glowacki, 1998).

ONFH is caused by the temporary or permanent loss of blood supply to the femoral head (Jones, 1999; Glueck et al., 2003; Childs, 2005). Therefore, it is hypothesized that variation in genes involved in angiogenesis by hypoxia might influence the development of ONFH. Previously, we reported that polymorphisms of $V E G F$ and $H I F-1 \alpha$, major target genes for angiogenesis and hypoxia, were associated with increased susceptibility to ONFH (Hong et al., 2007; Kim et al., 2008). These results suggested a genetic association between polymorphisms in genes related to angiogenesis and hypoxia and the development of ONFH. However, the genetic effects of many other genes involved in angiogenesis and hypoxia pathways on ONFH development have not been fully demonstrated. To further understand the genetic effects of angiogenesis- and hypoxia-related genes on ONFH, we selected candidate genes showing enhanced expression in hypoxic conditions using previously reported microarray data and SNPs from the dbSNP.

The candidate genes in this study, including $T F$, $K D R$, VEGFC, IGFBP3, NRP1, and ACE, are regulated by angiogenesis and hypoxia (Garcea et al., 2006), and have been implicated in various vascular diseases (Beckman et al., 1998; Padro et al., 2002). Transferrin (TF) is essential for iron 
Table 2. Subgroup association between candidate gene polymorphisms with ONFH among ONFH cases and controls.

\begin{tabular}{|c|c|c|c|c|c|c|c|c|c|c|}
\hline \multirow{2}{*}{ Subgroup } & \multirow[b]{2}{*}{ Gene } & \multirow{2}{*}{$\begin{array}{l}\text { SNP rs } \\
\text { ID }\end{array}$} & \multicolumn{2}{|c|}{ Codominant } & \multicolumn{2}{|c|}{ Dominant } & \multicolumn{2}{|l|}{ Recessive } & \multicolumn{2}{|l|}{ Allele } \\
\hline & & & $\begin{array}{c}\text { OR } \\
(95 \% \mathrm{Cl})^{\mathrm{a}}\end{array}$ & $P^{\mathrm{a}}$ & $\begin{array}{c}\text { OR } \\
(95 \% \mathrm{Cl})^{\mathrm{a}}\end{array}$ & $P^{a}$ & $\begin{array}{c}\text { OR } \\
(95 \% \mathrm{Cl})^{\mathrm{a}}\end{array}$ & $P^{a}$ & OR $(95 \% \mathrm{Cl})^{\mathrm{a}}$ & $P^{a}$ \\
\hline \multirow{17}{*}{ Alcohol } & \multirow[t]{4}{*}{ TF } & rs1525889 & $1.02(0.78-1.34)$ & 0.8876 & $1.14(0.77-1.69)$ & 0.5252 & $0.86(0.51-1.45)$ & 0.5747 & $1.02(0.77-1.35)$ & 0.8854 \\
\hline & & rs1880669 & $1.17(0.90-1.53)$ & 0.2304 & $1.38(0.91-2.11)$ & 0.1326 & $1.11(0.71-1.73)$ & 0.6531 & $1.19(0.91-1.56)$ & 0.2131 \\
\hline & & rs2692695 & $1.27(0.96-1.67)$ & 0.0920 & $1.64(1.04-2.60)$ & 0.0332 & $1.16(0.74-1.81)$ & 0.5250 & $1.28(0.97-1.68)$ & 0.0865 \\
\hline & & rs2718806 & $1.64(0.98-2.74)$ & 0.0626 & $1.69(0.97-2.92)$ & 0.0633 & $2.15(0.19-23.93)$ & 0.5349 & $1.65(0.98-2.76)$ & 0.0595 \\
\hline & \multirow[t]{2}{*}{ KDR } & rs6837735 & $0.95(0.73-1.25)$ & 0.7222 & $0.96(0.63-1.47)$ & 0.8505 & $0.91(0.58-1.44)$ & 0.6885 & $0.95(0.73-1.25)$ & 0.7192 \\
\hline & & rs1870377 & $0.90(0.69-1.18)$ & 0.4528 & $1.07(0.72-1.60)$ & 0.7458 & $0.62(0.37-1.04)$ & 0.0713 & $0.90(0.68-1.19)$ & 0.4468 \\
\hline & \multirow[t]{3}{*}{ VEGFC } & rs1485766 & $1.35(1.02-1.78)$ & 0.0345 & $1.52(0.98-2.36)$ & 0.0636 & $1.45(0.92-2.28)$ & 0.1140 & $1.34(1.02-1.75)$ & 0.0365 \\
\hline & & rs2333496 & $0.91(0.69-1.20)$ & 0.5061 & $1.03(0.69-1.52)$ & 0.9036 & $0.67(0.39-1.15)$ & 0.1457 & $0.91(0.69-1.20)$ & 0.4979 \\
\hline & & rs3775203 & $1.37(1.04-1.80)$ & 0.0259 & $1.59(1.03-2.46)$ & 0.0347 & $1.43(0.90-2.28)$ & 0.1348 & $1.36(1.04-1.79)$ & 0.0265 \\
\hline & \multirow[t]{2}{*}{ IGFBP3 } & rs3110697 & $1.18(0.85-1.64)$ & 0.3097 & $1.12(0.76-1.64)$ & 0.5792 & $1.98(0.80-4.92)$ & 0.1398 & $1.168(0.86-1.60)$ & 0.3300 \\
\hline & & rs2453839 & $1.30(0.90-1.87)$ & 0.1598 & $1.15(0.75-$ & 0.5227 & $6.15(1.34-28.22)$ & 0.0194 & $1.31(0.91-1$ & \\
\hline & \multirow[t]{3}{*}{ NRP1 } & rs12573218 & $0.68(0.45-1.03)$ & 0.0654 & $0.68(0.44-1.06)$ & 0.0881 & $0.31(0.03-2.87)$ & 0.3002 & $0.70(0.47-1.04)$ & 0.0805 \\
\hline & & rs12358370 & $0.59(0.34-1.03)$ & 0.0643 & $0.56(0.31$ & 0.0534 & $0.81(0.06-11.72)$ & 0.8775 & 0.59 & 0.0632 \\
\hline & & rs2269091 & $0.86(0.60-1.24)$ & 0.4241 & 0.89 (0.59- & 0.5661 & $0.56(0$. & 0.3459 & $0.87(0.61-1$ & 0.4290 \\
\hline & \multirow[t]{3}{*}{ ACE } & rs4309 & $1.22(0.92-1.61)$ & 0.1711 & $1.66(1.09-2.51)$ & 0.0178 & $0.89(0.53-1.48)$ & 0.6499 & $1.20(0.92-1.58)$ & 0.1825 \\
\hline & & rs4344 & $1.21(0.92-1.60)$ & 0.1746 & $1.62(1.08-2.45)$ & 0.0204 & $0.89(0.5$ & 0.6579 & $1.21(0.92-1.59)$ & 0.1791 \\
\hline & & rs4461142 & $1.17(0.88-1.54)$ & 0.2731 & $1.16(0.77-1.76)$ & 0.4861 & $1.33(0.81-2.20)$ & 0.2590 & $1.16(0.88-1.53)$ & 0.2783 \\
\hline \multirow[t]{17}{*}{ Idiopathic } & \multirow[t]{4}{*}{ TF } & rs1525889 & $1.21(0.91-1.61)$ & 0.1805 & $1.59(1.04-2.41)$ & 0.0309 & $0.93(0.55-1.56)$ & 0.7705 & $1.20(0.91-1.58)$ & 0.1915 \\
\hline & & rs1880669 & $1.38(1.05-1.81)$ & 0.0204 & $2.06(1.29-3.27)$ & 0.0023 & $1.17(0.76-1.82)$ & 0.4801 & $1.38(1.05-1$ & 0.0201 \\
\hline & & rs2692695 & $1.41(1.07-1.87)$ & 0.0160 & $2.37(1.43-3.92)$ & 0.0008 & $1.14(0.73-1.76)$ & 0.5676 & 1.39 (1.06-1.83) & 0.0175 \\
\hline & & rs2718806 & $1.64(0.97-2.77)$ & 0.0665 & $1.72(1.00-2.95)$ & 0.0486 & $0(0, \infty)$ & 0.9868 & $1.60(0.96-2.67)$ & 0.0727 \\
\hline & \multirow[t]{2}{*}{ KDR } & rs6837735 & $0.68(0.5$ & 0.0085 & $0.79(0.52$ & 0.2886 & $0.42(0.25$ & 0.0011 & $.92)$ & 0.0107 \\
\hline & & rs1870377 & $0.95(0.73$ & 0.7372 & $1.20(0.8$ & 0.3786 & 0.64( & 0.0939 & & 0.7373 \\
\hline & VEGFC & rs1485766 & $1.59(1.20-2.1)$ & 0.0011 & $2.26(1.39-3.66)$ & 0.0010 & $1.55(1.01-2.39)$ & 0.0456 & $1.56(1.19-2.04)$ & 0.0012 \\
\hline & & rs2333496 & $0.70(0.53-0.93)$ & 0.0152 & $0.78(0.53-1.15)$ & 0.2032 & $0.36(0.18-0.70)$ & 0.0027 & $0.70(0.52-0.93)$ & 0.0136 \\
\hline & & rs3775203 & $1.38(1.05-1.80)$ & 0.0197 & $1.53(0.99-2.38)$ & 0.0577 & $1.54(1.00-2.39)$ & 0.0521 & 1.39 (1.06-1.83) & 0.0168 \\
\hline & IGFBP3 & rs3110697 & $0.97(0.70-1.32)$ & 0.8226 & $0.77(0.52-1.14)$ & 0.1941 & $2.28(1.03-5.05)$ & 0.0416 & $0.97(0.71-1.32)$ & 0.8246 \\
\hline & & rs2453839 & $1.46(1.02-2.09)$ & 0.0375 & $1.30(0.87-1.96)$ & 0.1919 & $8.67(1.83-41.18)$ & 0.0066 & & 0.0414 \\
\hline & NRP1 & rs12573218 & $0.58(0.38-0.88)$ & 0.0114 & $0.55(0.35-0.87)$ & 0.0112 & $0.51(0.10-2.77)$ & 0.4378 & $0.61(0.41-0.91)$ & 0.0163 \\
\hline & & rs12358370 & $0.49(0.27-0.90)$ & 0.0211 & $0.49(0.26-0.92)$ & 0.0270 & $0(0, \infty)$ & 0.9875 & $0.49(0.27-0.90)$ & 0.0207 \\
\hline & & rs2269091 & $0.68(0.47-0.99)$ & 0.0419 & $0.64(0.42-0.97)$ & 0.0355 & $0.68(0.20-2.26)$ & 0.5271 & $0.69(0.48-0.99)$ & 0.0446 \\
\hline & ACE & rs4309 & $1.17(0.90-1.52)$ & 0.2507 & $1.17(0.78-1.74)$ & 0.4454 & $1.33(0.83-2.15)$ & 0.2383 & $1.18(0.90-1.55)$ & 0.2344 \\
\hline & & rs4344 & $1.06(0.80-1.39)$ & 0.6926 & $1.08(0.72-1.62)$ & 0.6990 & 1.07( & 0.8053 & 40) & 6874 \\
\hline & & rs4461142 & $1.50(1.14-2.00)$ & 0.0045 & $1.99(1.28-3.09)$ & 0.0022 & $1.42(0.88-2.29)$ & 0.1552 & $1.47(1.12-1.93)$ & 0.0053 \\
\hline Steroid & TF & rs1525889 & $1.14(0.74-1.76)$ & 0.5410 & $1.24(0.65-2.36)$ & 0.5239 & $1.15(0.52-2.54)$ & 0.7388 & $1.15(0.74-1.78)$ & 0.5350 \\
\hline & & rs1880669 & $1.06(0.70-1.61)$ & 0.7798 & $1.00(0.52-1.94)$ & 0.9991 & $1.19(0.59-2.40)$ & 0.6307 & $1.07(0.69-1.64)$ & 0.7729 \\
\hline & & rs2692695 & $1.03(0.68-1.58)$ & 0.8771 & $0.96(0.49-1.89)$ & 0.9078 & $1.15(0.57-2.32)$ & 0.7019 & $1.04(0.67-1.60)$ & 0.8742 \\
\hline & & rs2718806 & $0.90(0.34-2.35)$ & 0.8223 & $0.91(0.34-2.41)$ & 0.8427 & $0(0, \infty)$ & 0.9914 & $0.90(0.35-2.32)$ & 0.8255 \\
\hline & KDR & rs6837735 & $0.85(0.55-1.31)$ & 0.4500 & $0.70(0.35-1.38)$ & 0.2960 & $0.93(0.49-1.91)$ & 0.8503 & $0.85(0.55-1.31)$ & 0.4514 \\
\hline & & rs1870377 & $1.12(0.74-1.72)$ & 0.5890 & $1.44(0.74-2.82)$ & 0.2868 & $0.89(0.41-1.94)$ & 0.7662 & $1.13(0.73-1.74)$ & 0.5814 \\
\hline & VEGFC & rs1485766 & $0.96(0.63-1.48)$ & 0.8677 & $0.99(0.51-1.92)$ & 0.9656 & $0.91(0.43-1.92)$ & 0.8110 & $0.96(0.626-1.483)$ & 0.8662 \\
\hline & & rs2333496 & $0.90(0.58-1.40)$ & 0.6473 & $0.99(0.53-1.85)$ & 0.9667 & $0.69(0.28-1.70)$ & 0.4133 & $0.90(0.575-1.407)$ & 0.6422 \\
\hline & & rs3775203 & $1.31(0.85-2.02)$ & 0.2224 & $1.74(0.84-3.62)$ & 0.1369 & $1.18(0.57-2.44)$ & 0.6520 & $1.31(0.85-2.03)$ & 0.2194 \\
\hline & IGFBP3 & rs3110697 & $1.17(0.70-1.98)$ & 0.5491 & $1.10(0.59-2.04)$ & 0.7685 & $1.87(0.51-6.84)$ & 0.3445 & $1.15(0.71-1.85)$ & 0.5811 \\
\hline & & rs2453839 & & 0.1240 & $1.50(0.80-2.84)$ & 0.2090 & $4.94(0.61-40.06)$ & 0.1349 & $1.50(0.87-2.58)$ & \\
\hline & NRP1 & rs12573218 & $0.51(0.25-1.04)$ & 0.0641 & $0.54(0.26-1.13)$ & 0.1041 & $0(0, \infty)$ & 0.9831 & $0.58(0.31-1.09)$ & 0.0920 \\
\hline & & rs12358370 & $0.75(0.32-1.78)$ & 0.5148 & $0.78(0.32-1.91)$ & 0.5808 & $0(0, \infty)$ & 0.9908 & $0.75(0.32-1.78)$ & 0.5147 \\
\hline & & rs2269091 & $0.70(0.38-1.30)$ & 0.2574 & $0.74(0.38-1.42)$ & 0.3637 & $0(0, \infty)$ & 0.9806 & $0.73(0.41-1.30)$ & 0.2871 \\
\hline & ACE & rs4309 & $1.61(1.03-2.51)$ & 0.0374 & $3.68(1.63-8.33)$ & 0.0018 & $0.90(0.40-2.06)$ & 0.8085 & $1.57(1.02-2.42)$ & 0.0397 \\
\hline & & rs4344 & $1.54(0.97-2.43)$ & 0.0664 & $3.33(1.51-7.37)$ & 0.0029 & $0.76(0.31-1.89)$ & 0.5618 & $1.49(0.96-2.32)$ & 0.0741 \\
\hline & & rs4461142 & $1.56(0.98-2.48)$ & 0.0600 & $3.26(1.47-7.25)$ & 0.0037 & $0.83(0.34-2.02)$ & 0.6733 & $1.49(0.96-2.30)$ & 0.0729 \\
\hline
\end{tabular}

${ }^{\mathrm{a}}$ Logistic regression analyses were used for calculating $\mathrm{OR}(95 \% \mathrm{Cl})$ and $\mathrm{P}$ value. Dominant analysis: homozygotes for the major allele vs. heterozygotes vs. homozygotes for the minor allele. Recessive analysis: homozygotes for the minor allele vs. heterozygotes vs. homozygotes for the major allele. 
Table 3. Haplotype association between candidate gene polymorphisms and ONFH.

\begin{tabular}{|c|c|c|c|c|c|c|c|}
\hline $\begin{array}{l}\text { Haplo- } \\
\text { type }^{a}\end{array}$ & $\begin{array}{l}\text { Chromo- } \\
\text { some }\end{array}$ & Gene & Haplotype & SNP markers & Frequency & Haplotype OR ${ }^{a}$ & $P^{b}$ \\
\hline ht1 & 3 & TF & C-G-G-C-C & $\begin{array}{l}\text { rs1880669-rs2692695- } \\
\text { rs2718806-rs1525889- } \\
\text { rs1049296 }\end{array}$ & 0.411 & $1.10(0.87-1.39)$ & 0.4366 \\
\hline ht2 & & & T-A-G-A-T & & 0.252 & $0.72(0.55-0.94)$ & 0.0151 \\
\hline ht3 & & & T-A-G-A-C & & 0.247 & $0.99(0.76-1.29)$ & 0.9483 \\
\hline ht4 & & & C-G-A-A-C & & 0.080 & $1.48(0.95-2.30)$ & 0.0832 \\
\hline ht5 & 4 & KDR & C-T & rs2305949-rs6837735 & 0.465 & $0.81(0.65-1.01)$ & 0.0553 \\
\hline ht6 & & & C-C & & 0.391 & $1.32(1.06-1.65)$ & 0.0146 \\
\hline ht7 & & & $\mathrm{T}-\mathrm{C}$ & & 0.144 & $0.90(0.66-1.22)$ & 0.4910 \\
\hline ht8 & & & T-C-A & $\begin{array}{l}\text { rs12502008-rs7667298- } \\
\text { rs2071559 }\end{array}$ & 0.608 & $1.01(0.81-1.27)$ & 0.9059 \\
\hline ht9 & & & G-T-G & & 0.322 & $1.20(0.94-1.52)$ & 0.1386 \\
\hline ht10 & & & G-C-A & & 0.066 & $0.52(0.34-0.80)$ & 0.0026 \\
\hline ht11 & 7 & IGFBP3 & G-G-T & $\begin{array}{l}\text { rs3110697-rs6953668- } \\
\text { rs9282734 }\end{array}$ & 0.742 & $0.95(0.74-1.22)$ & 0.6854 \\
\hline ht12 & & & A-G-T & & 0.170 & $1.03(0.77-1.38)$ & 0.8395 \\
\hline ht13 & & & $A-A-G$ & & 0.088 & $1.05(0.71-1.53)$ & 0.8235 \\
\hline ht14 & 10 & NRP1 & C-G-G & $\begin{array}{l}\text { rs12573218-rs1331324- } \\
\text { rs11009340 }\end{array}$ & 0.526 & $1.04(0.82-1.30)$ & 0.7690 \\
\hline ht15 & & & C-C-T & & 0.271 & $1.31(1.00-1.72)$ & 0.0505 \\
\hline ht16 & & & T-C-G & & 0.142 & $0.67(0.49-0.92)$ & 0.0118 \\
\hline ht17 & & & C-C-G & & 0.054 & $1.12(0.68-1.84)$ & 0.6572 \\
\hline
\end{tabular}

${ }^{a}$ Values were constructed by the EM algorithm with genotyped SNP, ${ }^{b}$ Logistic regression analysis was used for calculating the $\mathrm{OR}(95 \% \mathrm{Cl})$ and $P$-value.

regulation involved in the hypoxia and angiogenesis pathway. TF promotes migration and invasion of endothelial cells and thus is an essential angiogenesis factor produced by hypertrophic cartilage during endochondral bone formation (Carlevaro et al., 1997; Li et al., 2003). VEGFC is another essential factor for angiogenesis and endothelial cell growth, and participates in the progression and development of angiogenic diseases (Cao et al., 1998). Angiotensin I converting enzyme (ACE) plays a key role in the rennin-angiotensin system and has been associated with various diseases, including coronary artery disease, type 2 diabetes, hypertension, stroke, and lupus (Saeed et al., 2005; Tsai et al., 2007; Yamagishi et al., 2007). In addition, ACE has been identified as a representative candidate gene in cardiovascular diseases (Niu et al., 2002). Kinase insert domain receptor (KDR) and neuropilin 1 (NRP1), which are VEGF receptors, are expressed in most vascular endothelial cells and regulate angiogenesis and cell migration, survival, and proliferation. Furthermore, KDR is related to the degree of bone marrow angiogenesis and is required for tumor neovascularization (Padro et al., 2002). KDR polymorphisms have been associated with a risk of coronary heart disease and cancer (Forsti et al., 2007; Wang et al., 2007).
In this study, we found that genetic variations in TF, VEGFC, IGFBP3, and ACE were associated with an increased risk of ONFH. Interestingly, however, KDR and NRP1 and one SNP in VEGF (rs2333496) had a protective effect against ONFH development. It is not clear why the SNPs in VEGF and its receptors that play critical roles in angiogenesis exert a protective effect on $\mathrm{ONFH}$. However, this effect may be related to the expression of VEGF in the edematous region of $\mathrm{ON}$ and its role in repairing ON (Radke et al., 2006).

ONFH patients were classified based on their etiology (alcohol-induced, idiopathic, and steroid-induced groups), and the SNPs that were associated with total ONFH showed differential association with these groups. SNPs of TF and $V E G F C$ in idiopathic ONFH and SNPs of ACE in the steroid subgroup were also found to be susceptibility factors for ONFH. Several SNPs of $K D R$ and NRP1 showed a protective effect against developing ONFH, particularly idiopathic ONFH. However, the sample size in steroid-induced groups is not enough to get power calculation. Further study is required to identify replications in large sample size of cases.

The most important finding in our report is that one SNP (rs2453839) of IGFBP3 is significantly 
associated with susceptibility to ONFH, especially alcohol-induced and idiopathic ONFH. Individuals bearing the minor allele genotype of rs2453839 showed a higher risk for ONFH than those bearing the common allele. IGFBP3 plays a role in promoting hypoxia-induced angiogenesis (Granata et al., 2007; Li et al., 2007). Among IGFBP members, IGFBP3 is most abundant in the circulatory system and is associated with atherosclerosis (Jones and Clemmons, 1995). Several polymorphisms in the IGFBP3 gene are also associated with cancer risk (Granata et al., 2007; Li et al., 2007). However, this SNP was associated only with ONFH, suggesting that IGFBP3 rs2453839 is relatively specific for ONFH.

In addition, as shown in the association analysis of SNPs (Tables 1 and 2), the KDR-ht10 and NRP-ht16 haplotypes were associated with decreased risk of ONFH. Particularly, the minor allele (T) of rs12573218 in the NRP1 gene contributed to the protective effect against ONFH. However, KDR-ht6 was associated with an increased risk of ONFH. This result suggests that the major allele $(\mathrm{C})$ of rs6837735 in the KDR gene contributes to the risk of ONFH. TF-ht2 also showed a protective association against ONFH, which is different from the individual SNP analyses. Therefore, these data suggest that ONFH is significantly associated with a specific candidate gene haplotype.

In conclusion, we investigated the genetic association of candidate genes related to angiogenesis and hypoxia with ONFH. The strongest association with ONFH correlated with a single SNP (rs2453839) in the IGFBP3 gene, and this SNP may act as a diagnostic marker for ONFH. In addition, other SNPs also can be considered for the prediction of susceptibility or resistance to ONFH.

\section{Methods}

\section{Subjects}

A total of 460 unrelated patients with ONFH (377 men, 83 women; age: $49.7 \pm 13.3 \mathrm{yr}$ ) and 300 unrelated control subjects (210 men, 90 women; age: $52.1 \pm 10.6 \mathrm{yr}$ ) were consecutively enrolled at the Kyungpook National University Hospital (Daegu, Korea) from 2002 to 2006. ONFH diagnoses were established by evidence of osteonecrosis through magnetic resonance imaging (MRI) in Stage 1 of the Association Research Circulation Osseous (ARCO) classification system and plain radiographs in Stages 2, 3, and 4. Control subjects were defined in the following way: they had no hip pain, and anteroposterior and frog leg lateral pelvic radiographs did not show any lesions with a sclerotic margin or subchondral collapse consistent with
ONFH. According to etiological factors, ONFH cases were classified into one of the following subgroups: alcohol-induced (215 cases), idiopathic (186 cases), and steroid-induced osteonecrosis (59 cases). Cases with a demonstrable history of direct trauma or with the possibility of a combination of causes were excluded. Steroid-induced osteonecrosis was defined by a history of taking prednisolone $(1,800 \mathrm{mg})$ or an equivalent over 4 weeks with nephritic syndrome, systemic lupus erythematosus, rheumatoid arthritis, allergic asthma, or organ transplantation. Alcohol-induced osteonecrosis was diagnosed by the consumption of more than $400 \mathrm{ml}$ of pure ethanol per week or alcohol-induced fatty liver and liver cirrhosis. All individuals provided informed consent for their participation in the study, and this project was approved by the Institutional Review Board.

\section{Candidate gene and SNP selection}

To identify genetic factors associated with the risk of $\mathrm{ONFH}$, we examined previous microarray data from bone marrow cells in hypoxic conditions. Normal and human mesenchymal stem cells (hMSC) were prepared from femoral tissue from osteoarthritis, osteoarthritic human chondrocytes, and the femur fracture in rat. Human and mouse bone marrow-derived MSCs from normoxic and hypoxic conditions were also used (Pacicca et al., 2003; Wieczorek et al., 2003; Salim et al., 2004; Tardif et al., 2004; Fang et al., 2005; Hopwood et al., 2005; Zhou et al., 2005).

For this study, we chose candidate genes associated with angiogenesis, lipid metabolism, oxidative stress, and hypoxia, the major pathogenic conditions of ONFH, on the basis of their known biological function and supportive literature. Approximately 3,000 SNPs for genotyping candidate genes were obtained from public databases (dbSNP. KSNP, HapMap) for verification. We primarily tested for SNPs in candidate genes known to regulate angiogenesis by hypoxia (Supplemental Data Table S1).

\section{Genotyping}

DNA was extracted from samples using the FlexiGene DNA Kit (QIAGEN) and was quantified using PicoGreen (Invitrogen). The genotyping of DNA samples was performed using an Affymetrix Targeted Genotyping $3 \mathrm{~K}$ Chip array according to the manufacturer's protocols. The Targeted Genotyping (TG) chip using molecular inversion probe technology with Gene chip universal microarrays provides a method that is capable of analyzing thousands of variants in a single reaction. In brief, a mixture of $2 \mu \mathrm{g}$ of genomic DNA and molecular inversion probes is heat denatured and brought to annealing temperature. MIP probes have two specific homology sequences that leave a 1-bp gap when hybridized to the genome. They also contain specific tag sequences that are ultimately read on the microarray. In addition to these elements that are specific to each probe, there are two PCR primers that are common to all probes. These primers face away from each other and therefore cannot facilitate the amplification. After the probes are hybridized, the reaction is split into four tubes, with one of the four nucleotides added to each tube. 
When the gap is filled in with the appropriate nucleotide, a unimolecular ligation event is catalyzed. After eliminating the linear probes with exonucleases, PCR, using the common primers that now face each other, is performed in the four tubes. In addition to signal amplification, a fluorescent label is introduced by a PCR primer into each of the four tubes. The four reactions are then mixed and hybridized onto a tag array. The arrays are washed and loaded onto a GeneChip Scanner 3000 7G (Affymetrix). Images are then analyzed using GCOS software (Affymetrix). Finally, the TG analysis software measures the data quality and generates genotypes for arrays that have met a specific set of quality control criteria.

\section{Statistical and haplotype analyses}

Permutation tests were used to determine whether individual variants were in equilibrium at each locus in the population (Hardy-Weinberg equilibrium). Logistical regression analyses were used to calculate the odds ratios (OR), 95\% confidence intervals (Cl), and corresponding $\mathrm{P}$-values of each SNP and haplotypes controlling for age and sex as covariates. We consider the genetic models of dominant, recessive, and codominant SNPs and haplotypes. Genotypes were given codes of 0,1 , and 2; 0,0 , and 1 ; or 0,0 , and 1 in the codominant, dominant, and recessive models, respectively. We examined Lewontin's $D^{\prime}\left(\left|D^{\prime}\right|\right)$ and the linkage disequilibrium (LD) coefficient $r^{2}$ between all pairs of biallelic loci (Hedrick, 1987). Haplotype structures and their frequencies were estimated from genotyped data for the eight SNPs within the linkage disequilibrium block using Haploview version 3.32 (http://www.broad.mit.edu/mpg/haploview/), which estimates the haplotype by an accelerated EM algorithm similar to the partition ligation method (Qin et al., 2002). The Haploview program was also used to calculate pairwise linkage disequilibrium ( $D^{\prime}$ and $r^{2}$ ) for each mark pair. All analyses were two-tailed, and a $P$-value of $<0.05$ was considered statistically significant. Statistics were performed using SAS 9.1 (SAS Institute Inc., Cary, NC).

\section{Supplemental data}

Supplemental Data include two tables and a figure andcan be found with this article online at http://e-emm.or.kr/ article/article_files/ SP-42-5-07.pdf.

\section{Acknowledgments}

This work was supported by the Korea Health 21 R\&D Project, Ministry of Health \& Welfare (Project No.: A010252) and in part by the Korea Science and Engineering Foundation (KOSEF) grant funded by the Korea government (MEST) (R13-2008-009-01003-0).

\section{References}

Arnett TR, Gibbons DC, Utting JC, Orriss IR, Hoebertz A, Rosendaal M, Meghji S. Hypoxia is a major stimulator of osteoclast formation and bone resorption. J Cell Physiol 2003;196:2-8
Beckman LE, Van Landeghem GF, Sikstrom C, Beckman L. DNA polymorphisms and haplotypes in the human transferrin gene. Hum Genet 1998;102:141-4

Bjorkman A, Svensson PJ, Hillarp A, Burtscher IM, Runow $A$, Benoni $G$. Factor $V$ leiden and prothrombin gene mutation: risk factors for osteonecrosis of the femoral head in adults. Clin Orthop Relat Res 2004:168-72

Cao Y, Linden P, Farnebo J, Cao R, Eriksson A, Kumar V, Qi $\mathrm{JH}$, Claesson-Welsh L, Alitalo K. Vascular endothelial growth factor $C$ induces angiogenesis in vivo. Proc Nat Acad Sci USA 1998;95:14389-94

Carlevaro MF, Albini A, Ribatti D, Gentili C, Benelli R, Cermelli $S$, Cancedda R, Cancedda FD. Transferrin promotes endothelial cell migration and invasion: implication in cartilage neovascularization. J Cell Biol 1997;136:1375-84

Childs SG. Osteonecrosis: death of bone cells. Orthop Nurs 2005;24:295-301; quiz 302-3

Colnot C, Thompson Z, Miclau T, Werb Z, Helms JA. Altered fracture repair in the absence of MMP9. Development 2003;130:4123-33

Fang TD, Salim A, Xia W, Nacamuli RP, Guccione S, Song HM, Carano RA, Filvaroff EH, Bednarski MD, Giaccia AJ, Longaker MT. Angiogenesis is required for successful bone induction during distraction osteogenesis. J Bone Miner Res 2005;20:1114-24

Fong KD, Nacamuli RP, Loboa EG, Henderson JH, Fang TD, Song HM, Cowan CM, Warren SM, Carter DR, Longaker MT. Equibiaxial tensile strain affects calvarial osteoblast biology. J Craniofac Surg 2003;14:348-55

Forsti A, Jin Q, Altieri A, Johansson R, Wagner K, Enquist K, Grzybowska E, Pamula J, Pekala W, Hallmans G, Lenner P, Hemminki K. Polymorphisms in the KDR and POSTN genes: association with breast cancer susceptibility and prognosis. Breast Cancer Res Treat 2007;101:83-93

Garcea G, Doucas H, Steward WP, Dennison AR, Berry DP. Hypoxia and angiogenesis in pancreatic cancer. ANZ J Surg 2006;76:830-42

Glowacki J. Angiogenesis in fracture repair. Clin Orthop Relat Res 1998:S82-9

Glueck CJ, Freiberg RA, Fontaine RN, Tracy T, Wang P. Hypofibrinolysis, thrombophilia, osteonecrosis. Clin Orthop Relat Res 2001:19-33

Glueck CJ, Freiberg RA, Wang P. Role of thrombosis in osteonecrosis. Curr Hematol Rep 2003;2:417-22

Granata R, Trovato L, Lupia E, Sala G, Settanni F, Camussi G, Ghidoni R, Ghigo E. Insulin-like growth factor binding protein-3 induces angiogenesis through IGF-I- and SphK1-dependent mechanisms. J Thromb Haemost 2007; 5:835-45

Harper J, Klagsbrun M. Cartilage to bone--angiogenesis leads the way. Nat Med 1999;5:617-8

Hedrick PW. Gametic disequilibrium measures: proceed with caution. Genetics 1987;117:331-41

Hickey MM, Simon MC. Regulation of angiogenesis by hypoxia and hypoxia-inducible factors. Curr Top Dev Biol 


\section{6;76:217-57}

Hong JM, Kim TH, Chae SC, Koo KH, Lee YJ, Park EK, Choi JY, Ryoo HM, Kim SY. Association study of hypoxia inducible factor 1alpha (HIF1alpha) with osteonecrosis of femoral head in a Korean population. Osteoarthritis Cartilage 2007;15:688-94

Hopwood B, Gronthos S, Kuliwaba JS, Robey PG, Findlay $\mathrm{DM}$, Fazzalari NL. Identification of differentially expressed genes between osteoarthritic and normal trabecular bone from the intertrochanteric region of the proximal femur using cDNA microarray analysis. Bone 2005;36:635-44

Jones JI, Clemmons DR. Insulin-like growth factors and their binding proteins: biological actions. Endocr Rev 1995;16: 3-34

Jones JP, Jr. Coagulopathies and osteonecrosis. Acta Orthop Belg 1999;65 Suppl 1:5-8

Kerachian MA, Harvey EJ, Cournoyer D, Chow TY, Seguin C. Avascular necrosis of the femoral head: vascular hypotheses. Endothelium 2006;13:237-44

Kim TH, Hong JM, Lee JY, Oh B, Park EK, Lee CK, Bae SC, Kim SY. Promoter polymorphisms of the vascular endothelial growth factor gene is associated with an osteonecrosis of the femoral head in the Korean population. Osteoarthritis Cartilage 2008;16:287-91

Komatsu DE, Hadjiargyrou M. Activation of the transcription factor HIF-1 and its target genes, VEGF, HO-1, iNOS, during fracture repair. Bone 2004;34:680-8

Komatsu DE, Bosch-Marce M, Semenza GL, Hadjiargyrou $M$. Enhanced bone regeneration associated with decreased apoptosis in mice with partial HIF-1alpha deficiency. J Bone Miner Res 2007;22:366-74

Lattimore JD, Wilcox I, Nakhla S, Langenfeld M, Jessup W, Celermajer DS. Repetitive hypoxia increases lipid loading in human macrophages-a potentially atherogenic effect. Atherosclerosis 2005;179:255-9

Lewis JS, Lee JA, Underwood JC, Harris AL, Lewis CE. Macrophage responses to hypoxia: relevance to disease mechanisms. J Leukoc Biol 1999;66:889-900

Li H, Bubley GJ, Balk SP, Gaziano JM, Pollak M, Stampfer MJ, Ma J. Hypoxia-inducible factor-1alpha (HIF-1alpha) gene polymorphisms, circulating insulin-like growth factor binding protein (IGFBP)-3 levels and prostate cancer. Prostate 2007;67:1354-61

Li X, Fu GF, Fan YR, Shi CF, Liu XJ, Xu GX, Wang JJ. Potent inhibition of angiogenesis and liver tumor growth by administration of an aerosol containing a transferrinliposome-endostatin complex. World J Gastroenterol 2003; 9:262-6

Lin C, McGough R, Aswad B, Block JA, Terek R. Hypoxia induces HIF-1alpha and VEGF expression in chondrosarcoma cells and chondrocytes. J Orthop Res 2004;22: 1175-81

Ma HZ, Zeng BF, Li XL. Upregulation of VEGF in subchondral bone of necrotic femoral heads in rabbits with use of extracorporeal shock waves. Calcif Tissue Int 2007;81: $124-31$
Miyanishi K, Yamamoto T, Irisa T, Yamashita A, Jingushi S Noguchi Y, Iwamoto Y. Bone marrow fat cell enlargement and a rise in intraosseous pressure in steroid-treated rabbits with osteonecrosis. Bone 2002;30:185-90

Niu T, Chen X, Xu X. Angiotensin converting enzyme gene insertion/deletion polymorphism and cardiovascular disease: therapeutic implications. Drugs 2002;62:977-93

Pacicca DM, Patel N, Lee C, Salisbury K, Lehmann W, Carvalho R, Gerstenfeld LC, Einhorn TA. Expression of angiogenic factors during distraction osteogenesis. Bone 2003;33:889-98

Padro T, Bieker R, Ruiz S, Steins M, Retzlaff S, Burger H, Buchner T, Kessler T, Herrera F, Kienast J, Muller-Tidow C Serve H, Berdel WE, Mesters RM. Overexpression of vascular endothelial growth factor (VEGF) and its cellular receptor KDR (VEGFR-2) in the bone marrow of patients with acute myeloid leukemia. Leukemia 2002;16:1302-10

Qin ZS, Niu T, Liu JS. Partition-ligation-expectation- maximization algorithm for haplotype inference with single-nucleotide polymorphisms. Am J Hum Genet 2002;71: 1242-7

Radke S, Battmann A, Jatzke S, Eulert J, Jakob F, Schutze $\mathrm{N}$. Expression of the angiomatrix and angiogenic proteins CYR61, CTGF, and VEGF in osteonecrosis of the femoral head. J Orthop Res 2006;24:945-52

Saeed M, Mekan SF, Rabbani MA, Arain FM, Arif M, Shaharyar S. Angiotensin converting enzyme (ACE) gene polymorphisms and lupus disease severity: a promising link. Ann Rheum Dis 2005;64:164-5

Salim A, Nacamuli RP, Morgan EF, Giaccia AJ, Longaker MT. Transient changes in oxygen tension inhibit osteogenic differentiation and Runx2 expression in osteoblasts. J Biol Chem 2004;279:40007-16

Semenza GL. HIF-1 and human disease: one highly involved factor. Genes Dev 2000;14:1983-91

Semenza GL. Hypoxia-inducible factor 1: oxygen homeostasis and disease pathophysiology. Trends Mol Med 2001; $7: 345-50$

Stein I, Itin A, Einat P, Skaliter R, Grossman Z, Keshet E. Translation of vascular endothelial growth factor mRNA by internal ribosome entry: implications for translation under hypoxia. Mol Cell Biol 1998;18:3112-9

Suzuki O, Bishop AT, Sunagawa T, Katsube K, Friedrich PF. VEGF-promoted surgical angiogenesis in necrotic bone. Microsurgery 2004;24:85-91

Tardif G, Hum D, Pelletier JP, Boileau C, Ranger P, Martel-Pelletier J. Differential gene expression and regulation of the bone morphogenetic protein antagonists follistatin and gremlin in normal and osteoarthritic human chondrocytes and synovial fibroblasts. Arthritis Rheum 2004; 50:2521-30

Tsai CT, Hwang JJ, Ritchie MD, Moore JH, Chiang FT, Lai LP, Hsu KL, Tseng CD, Lin JL, Tseng YZ. Renin-angiotensin system gene polymorphisms and coronary artery disease in a large angiographic cohort: detection of high order gene-gene interaction. Atherosclerosis 2007;195:172-80 
Wang Y, Zheng Y, Zhang W, Yu H, Lou K, Zhang Y, Qin Q, Zhao B, Yang Y, Hui R. Polymorphisms of KDR gene are associated with coronary heart disease. J Am Coll Cardiol 2007;50:760-7

Wieczorek G, Steinhoff C, Schulz R, Scheller M, Vingron M, Ropers HH, Nuber UA. Gene expression profile of mouse bone marrow stromal cells determined by cDNA microarray analysis. Cell Tissue Res 2003;311:227-37
Yamagishi K, Tanigawa T, Cui R, Tabata M, Ikeda A, Yao M, Shimamoto $\mathrm{T}$, Iso $\mathrm{H}$. High sodium intake strengthens the association of ACE I/D polymorphism with blood pressure in a community. Am J Hypertens 2007;20:751-7

Zhou S, Lechpammer S, Greenberger JS, Glowacki J. Hypoxia inhibition of adipocytogenesis in human bone marrow stromal cells requires transforming growth factorbeta/Smad3 signaling. J Biol Chem 2005;280: 22688-96 